Original Research

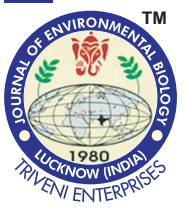

DOI : http://doi.org/10.22438/jeb/40/2/MRN-753
Journal Home page : www.jeb.co.in $\star$ E-mail : editor@jeb.co.in Journal of Environmental Biology CODEN: JEBIDP
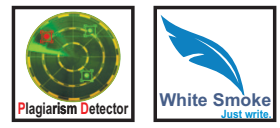

\title{
Correlation among physiological and histological changes in soybean seeds during storage
}

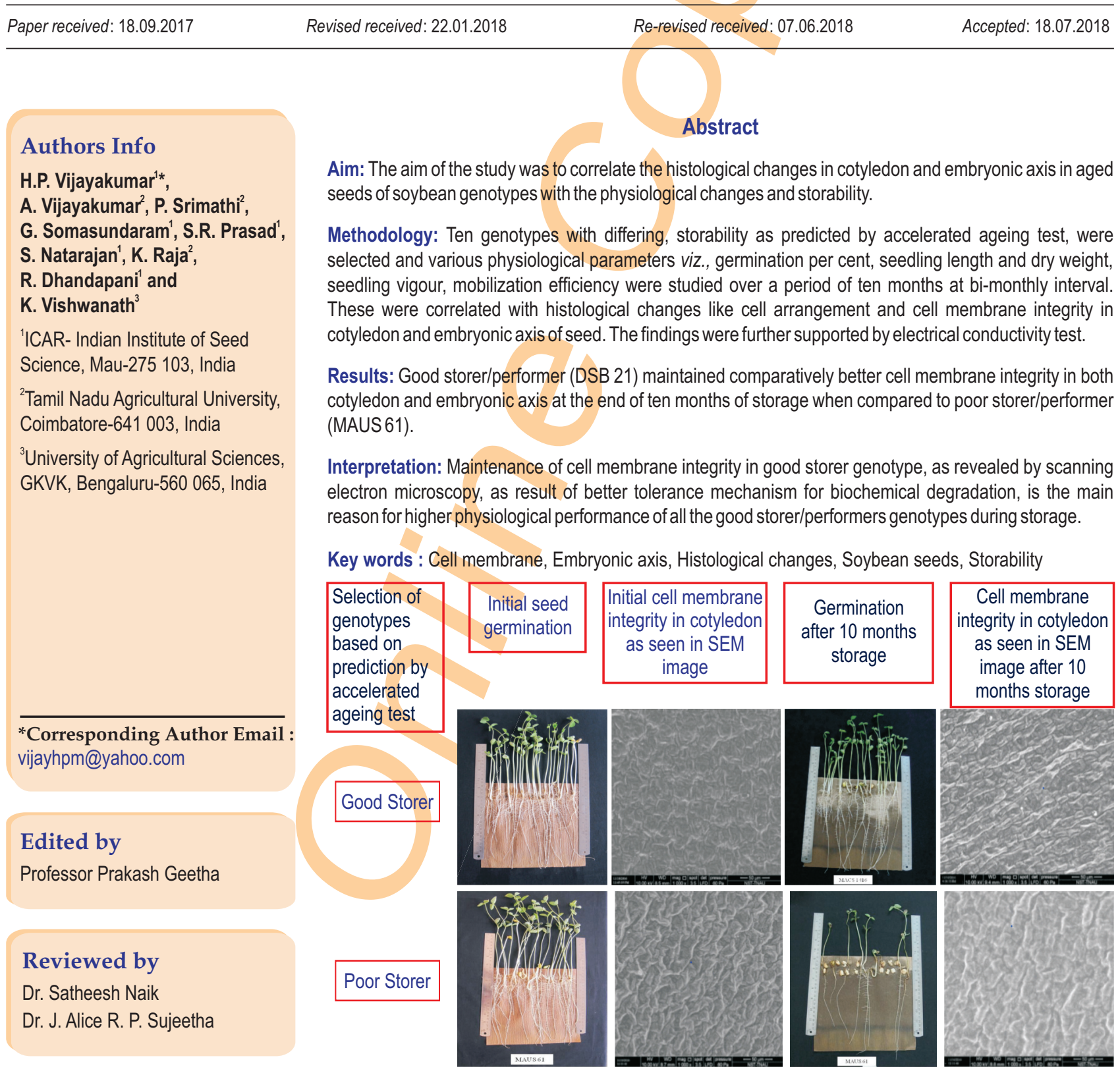

How to cite : Vijayakumar, H.P., A. Vijayakumar, P. Srimathi, G. Somasundaram, S.R. Prasad, S. Natarajan, K. Raja, R. Dhandapani and K. Vishwanath: Correlation among physiological and histological changes in soybean seeds during storage. J. Environ. Biol., 40, 217-225 (2019). 


\section{Introduction}

In the tropical and subtropical countries, storage of soybean seed has become a big challenge to the seed industry as seed loses viability below minimum seed certification standard (70\%) before the next growing season due to higher temperature. Deteriorated seeds in field produces uneven stands, spotty fields and fewer plants per hectare, there by, resulting in lower productivity (Kapoor et al., 2010; Biabani et al., 2011). Annual losses due to deterioration could be as much as 25 per cent of the harvested crop.

Storability of seeds is a genetically regulated character and is influenced by initial quality, pre-storage history, moisture content, relative humidity and temperature of storage environment; duration of storage and biotic agents (Khatun et al., 2009; Biabani et al., 2011). The storage life of seeds vary from species to species (Harrington, 1972) and even with in varieties of species (Basu et al., 2004). The mechanism of ageing that differ with varieties of same species is still not clear. The changes associated with ageing are many but differ among genotypes (Jain et al., 2006). Many processes associated with seed ageing during storage appears to be free-radical mediated, and lipid peroxidation is suggested to be a primary cause of deterioration in stored seeds (McDonald, 1999). The damage caused by lipid peroxidation can be visualized through scanning electronic microscope by studying the histological changes occurring during ageing and, thereby, help in identifying changes that are responsible for poor storability. In view of the above, a study was conducted to correlate physiological changes with histological changes in seeds of soybean genotypes during storage.

\section{Materials and Methods}

Seeds of 30 soybean genotypes were procured from different sources UAS, Dharwad; IARI, New Delhi; ICAR-IISR, Indore and Department of Pulses, TNAU, Coimbatore and they were multiplied under isoclimatic conditions at ARS, Bhavanisagar of TNAU, Coimbatore. Seeds were shade dried after harvesting to about $8.5 \%$ moisture content. These 30 genotypes were screened through accelerated ageing test for physiological parameters and identified five genotypes viz., Kalitur, EC 18761, MACS 1416, CO1 and DSB21 as good storers/performers and five genotypes viz., JS 71-05, DS 228, MAUS 61, NRC 93 and DSB 24 as poor storers/performer, based on germination per cent after accelerated ageing. Seeds of selected ten genotypes were stored in cloth bags under ambient conditions of Coimbatore for a period of ten months and they were evaluated for following physiological parameters at bi-monthly intervals. Seed moisture content was estimated as per ISTA (2007). Seed germination test was carried out using four replicates of 100 seeds in paper medium (ISTA, 2007) under laboratory conditions of $25 \pm 2^{\circ} \mathrm{C}$ temperature and $95 \pm 3$ per cent relative humidity. The number of normal seedlings was counted at the end of $8^{\text {th }}$ day and the means were expressed as germination per cent. On final count, ten normal seedlings were selected from the germination test at random in each replication. The seedling length was measured from base of primary leaf to tip of the primary root and the mean was calculated and expressed in centimeters. The seedlings used for growth measurement were taken from each replications and after removing their cotyledons and seed coat, they were dried in hot air oven maintained at $80 \pm$ $2^{\circ} \mathrm{C}$ for $24 \mathrm{hrs}$. Later, they were cooled in desiccator filled with silica gel for $30 \mathrm{~min}$. The dry matter of seedlings was weighed using an electronic balance and the mean was expressed as mg per seedling.

Seedling vigour index I and vigour index II values were computed using the formula as suggested by Abdul-Baki and Anderson (1973) and Reddy and Khan (2001). For estimating mobilization efficiency, three replicates of 25 seeds from each genotype were weighed individually and germinated in complete darkness. After seven days of germination, the cotyledons and seedling were separated, dried for $24 \mathrm{hrs}$ at $80 \pm 2^{\circ} \mathrm{C}$, cooled in a desiccator for half an hour and weighed. The reduction in dry weight of cotyledons and increase in dry weight of embryonic axes during germination period was estimated, and mobilization efficiency was calculated by the formula given by Srivastava and Sareen (1974).

For electrical conductivity test, four replicates of twenty five seeds were taken from each genotype and they were cleaned and weighed. The seeds were then soaked in pre-cooled $50 \mathrm{ml}$ of distilled water for $9 \mathrm{hrs}$ at $20^{\circ} \mathrm{C}$ temperature. After soaking duration, the beaker was swirled for 10 to $15 \mathrm{sec}$ and electrical conductivity of seed leachates was measured by immersing diptype cell of a digital conductivity meter having a cell constant of one (Hampton and TeKrony, 1995).

Scanning Electron Microscope FEI QUANTA 250 was used to study the histological changes in fresh and naturally aged seeds of one good storer (DSB 21) and one poor storer genotype (MAUS 61). Fresh seeds and 10 months stored seeds were preconditioned for $3 \mathrm{hrs}$ in between moist germination paper. Then embryonic axis and cotyledon were separated and dehydrated slowly by soaking in $25,50,70-75,90-95 \%$ ethanol for $20 \mathrm{~min}$ at each concentration followed by soaking in 100\% ethanol for $30 \mathrm{~min}$ (repeated twice) at room conditions and observed for cell arrangement pattern of embryonic axis and cotyledon.

Data obtained from experiment was analyzed statistically by adopting techniques described by Panse and Sukhatme (1985). Wherever necessary, the percent values were transformed to arc-sine values before analysis. The critical differences $(C D)$ were calculated at 5 and $1 \%$ probability level. 


\section{Results and Discussion}

Seed moisture content was significantly influenced by storage period and increased to $9.11 \%$ by the end of ten months of storage from initial level of $8.5 \%$ (Table 1) due to absorption of moisture and attainment of equilibrium with atmospheric moisture as seeds are hygroscopic in nature (Shelar et al., 2008). However, there was no significant difference among the genotypes with respect to seed moisture content.

With respect to physiological seed quality, significant decrease in seed germination was observed in all the genotypes but the reduction was slow in Kalitur, which maintained $87 \%$ germination after ten months of storage and was on par with MACS 1416 (86\%) (Table 1). In general, good performers screened from the accelerated ageing test maintained higher seed germination after 10 months of storage, where reduction was only $12 \%$ from initial germination. Genotypes classified as poor storers/performers showed drastic reduction of $55 \%$ from the initial which showed better reliability of accelerated ageing test in assessing seed storability. Similarly, Havstad et al. (2011) recommended accelerated ageing test for $24 \mathrm{hrs}$ at $43-45^{\circ} \mathrm{C}$ as appropriate test to assess seed vigour and storage potential of red clover, while Eksi and Demir (2011) demonstrated that controlled deterioration test of 5 days could identify differences in seed lot vigour and longevity in onion.
Lima et al.2 (2010) reported that seed deterioration in soybean genotypes was more influenced by the linolenic acid content than presence of lipoxygenase. The seed quality of genotype containing lipoxygenase with normal linolenic acid content was found to be worst. Hosamani et al. (2013) reported that black-seeded landraces of soybean such as T-49, Kalitur and Birsa-1 had better storability than yellow-seeded varieties. However, in the present study, yellow seeded genotypes also showed wider variability in seed quality characters, wherein EC 18761, MACS 1416, C01 and DSB 21 maintained higher seed viability during storage as compared to other yellow seeded soybean genotypes such as MAUS 61, NRC 93, DS 228, JS 7105 and DSB 24.

The genotypes which performed physiologically better in accelerated ageing test also maintained higher seedling length, dry matter production and seedling vigour over the storage period compared to poor performing genotypes. Mean seedling length significantly reduced after 4 months of seed storage and decreased to $29.6 \mathrm{~cm}$ after ten months of storage as compared to fresh seed $(39.1 \mathrm{~cm})$. Kalitur was found to produce longest seedlings $(38.5 \mathrm{~cm})$, while MAUS 61 produced shortest seedlings of $18 \mathrm{~cm}$ only (Table 2). The reduced seedling growth could be attributed to generation of free radicals during lipid peroxidation which damages cell organelles like mitochondria and leads to reduced mitochondria in cells and results in lower respiration and

Table 1: Seed moisture content (\%) and germination (\%) as influenced by genotypes and natural ageing period in soybean

\begin{tabular}{|c|c|c|c|c|c|c|c|c|c|c|c|c|c|c|}
\hline \multirow[t]{3}{*}{ Genotypes (G) } & \multicolumn{6}{|c|}{ Seed moisture content } & \multicolumn{6}{|c|}{ Germination Per cent } & & \multirow[t]{3}{*}{ Mean } \\
\hline & \multicolumn{6}{|c|}{ Storage Period (Months) (P) } & \multicolumn{7}{|c|}{ Storage Period (Months) (P) } & \\
\hline & Initial & & 4 & 6 & 8 & 10 & & Initial & 2 & 4 & 6 & 8 & 10 & \\
\hline \multicolumn{15}{|c|}{ Good performers in accelerated ageing test } \\
\hline MACS 1416 & 8.49 & 8.42 & 8.9 & 8.71 & 8.75 & 9.1 & 8.73 & $98(84.2)$ & $98(84.2)$ & $96(80.0)$ & $95(78.8)$ & $94(77.9)$ & $86(68.2)$ & $95(78.9)$ \\
\hline CO1 & 8.46 & 8.38 & 9.04 & 8.89 & 8.92 & 9.15 & 8.81 & $93(76.9)$ & $92(74.1)$ & $88(70.0)$ & $86(68.1)$ & $83(65.6)$ & $80(63.4)$ & $87(69.7)$ \\
\hline EC 18761 & 8.5 & 8.45 & 9.04 & 8.92 & 8.93 & 9.17 & 8.83 & $99(87.1)$ & $96(80.4)$ & $92(73.6)$ & $89(70.7)$ & $85(67.2)$ & $83(65.6)$ & $91(74.1)$ \\
\hline DSB 21 & 8.57 & 8.5 & 9.05 & 8.89 & 8.9 & 9.18 & 8.85 & $89(70.7)$ & $87(68.9)$ & $84(66.4)$ & $82(64.9)$ & $79(62.7)$ & $78(62.0)$ & $83(65.9)$ \\
\hline Kalitur & 8.52 & 8.49 & 8.93 & 8.78 & 8.85 & 9.09 & 8.77 & $94(77.7)$ & $94(77.9)$ & $91(72.6)$ & $90(71.6)$ & $88(69.8)$ & $87(69.1)$ & $91(73.1)$ \\
\hline \multicolumn{15}{|c|}{ Poor performers in accelerated ageing test } \\
\hline MAUS 61 & 8.44 & 8.37 & 9.05 & 8.94 & 8.95 & 9.13 & 8.81 & $95(79.1)$ & $90(74.1)$ & $84(66.5)$ & $75(60.8)$ & $34(35.6)$ & $5(8.7)$ & $64(54.1)$ \\
\hline DSB 24 & 8.55 & 8.51 & 8.82 & 8.73 & 8.75 & 8.98 & 8.72 & $89(71.2)$ & $88(69.8)$ & $82(64.9)$ & $76(60.7)$ & $71(57.4)$ & $60(50.7)$ & $78(62.5)$ \\
\hline NRC 93 & 8.52 & 8.48 & 8.82 & 8.76 & 8.78 & 9.03 & 8.73 & $87(69.4)$ & $85(67.2)$ & $78(62.0)$ & $69(56.1)$ & $62(51.9)$ & 25(29.9) & $68(56.1)$ \\
\hline DS 228 & 8.46 & 8.4 & 8.99 & 8.79 & 8.83 & 9.15 & 8.77 & $93(75.2)$ & $87(69.0)$ & $81(64.1)$ & $75(60.0)$ & $69(56.1)$ & $58(49.6)$ & $77(62.3)$ \\
\hline JS 71-05 & 8.48 & 8.41 & 9.01 & 8.85 & 8.9 & 9.17 & 8.8 & $90(71.8)$ & $85(67.2)$ & $79(62.7)$ & $72(58.0)$ & $67(54.9)$ & $54(47.2)$ & $75(60.3)$ \\
\hline Mean & 8.5 & 8.44 & 8.96 & 8.83 & 8.86 & 9.11 & & $93(76.3)$ & $90(73.3)$ & $86(68.3)$ & $81(65.0)$ & $73(59.9)$ & $62(51.5)$ & \\
\hline $\begin{array}{l}\text { Source of } \\
\text { variation }\end{array}$ & \multicolumn{3}{|c|}{ SEd } & \multicolumn{2}{|c|}{$\mathrm{CD}(\mathrm{P}=0.05)$} & \multicolumn{3}{|c|}{$\mathrm{CD}(\mathrm{P}=0.01)$} & SEd & \multicolumn{2}{|c|}{$\mathrm{CD}(\mathrm{P}=0.05)$} & \multicolumn{2}{|c|}{$\mathrm{CD}(\mathrm{P}=0.01)$} & \\
\hline \multirow{3}{*}{\multicolumn{2}{|c|}{$\begin{array}{l}\text { Genotype }(G) \\
\text { Storage period }(P) \\
\text { GxP }\end{array}$}} & \multirow{3}{*}{\multicolumn{2}{|c|}{$\begin{array}{l}0.04 \\
0.03 \\
0.11\end{array}$}} & \multirow{2}{*}{\multicolumn{2}{|c|}{$\begin{array}{l}\text { NS } \\
0.07\end{array}$}} & \multicolumn{3}{|l|}{ NS } & 1.4 & \multicolumn{2}{|l|}{2.76} & \multicolumn{2}{|l|}{3.64} & \\
\hline & & & & & & 0.09 & & & 1.08 & \multicolumn{2}{|l|}{2.14} & \multicolumn{2}{|l|}{2.82} & \\
\hline & & & & NS & & NS & & & 3.43 & 6.76 & & 8.93 & & \\
\hline
\end{tabular}

Values in parenthesis are arc sine transformed values 
energy metabolism (Mc Donald, 1999). All the genotypes showed significant decline in dry matter production, but MACS 1416 produced the highest dry matter $(39.9 \mathrm{mg})$ even after ten months of seed storage, which was on par with Kalitur (39.6 mg), DSB 21 (39.5 mg), DSB 24 (38.4 mg) EC 18761 (35.9 mg) and DS 228 $(34.9 \mathrm{mg})$. The lowest dry matter production was recorded in MAUS 61 (15.5 mg) (Table 2). Kapoor et al. (2010) observed significant decrease in all the physiological parameters in all the five chickpea varieties upon ageing and also found a differential response among varieties in tolerating ageing conditions.

There was a significant decrease of SVI I and SVI II in all the genotypes, however reduction was slow in Kalitur which maintained highest SVI I and SVI II (3351 and 3445) after a storage period of 10 months. MAUS 61 showed maximum decrease and recorded lowest SVI I and SVI II (90 and 78) (Table 3). There was only 27 and $26 \%$ reduction in SVI I and SVI II in good storers/performers after ten months of storage period but poor performing genotypes showed drastic reduction of 67 and $66 \%$ in SVI I and SVI II, respectively. Anuja and Aneja (2004) reported that soybean genotypes showed variability with respect to changes in the level of dehydrogenase, catalase, peroxidase, amylase, phosphatase and glutamic acid decarboxylase, which are associated with seed viability during storage. Such genotypic differences in capability to resist biochemical degradation resulted in variability in seedling vigour among genotypes.

Mobilization efficiency is the capacity of seed to mobilize the nutrients to the growing embryo. Mean mobilization efficiency significantly declined after each storage period and finally reached $39.5 \%$ on $10^{\text {th }}$ month of storage as compared to fresh seeds $(68.9 \%)$. The reactive oxygen species generated during ageing cause damage to enzymes that are essential to convert reserve food in the embryo to usable form and finally production of normal seedling (lqbal et al., 2002). Although mobilization efficiency decreased over the storage period in all the genotypes, the extent of reduction at ten months of storage varied significantly among the genotypes. Among the genotypes, good storers/performers maintained higher mobilization efficiency recording a reduction percentage of 22 over 10 months' period, while the poor storers/performers showed $64 \%$ reduction. MACS 1416 maintained highest mobilization efficiency $(58.8 \%)$ which was followed by Kalitur (57.3\%), while MAUS 61 could maintain only $2.1 \%$ (Table 4 ).

The genotypic variation in seed viability and seedling vigour of aged seeds was also observed by Basu et al. (2004) in maize; Zhang et al. (2006) in rapeseed and mustard and Kannababu et al. (2016) in sweet sorghum. Good storers/performers have better tolerant mechanisms for biochemical degradation which further manifested in better mobilization efficiency and physiological seed quality during seed storage when compared to poor performing genotypes.

Electrical conductivity (EC) of seed leachate i.e., leaching of sugars and leaching of amino acids were employed for evaluating the membrane integrity and correlated with seed vigour and viability (Mavi et al., 2014). In the present study, mean

Table 2 : Seedling length and dry matter production as influenced by genotypes and natural ageing period in soybean

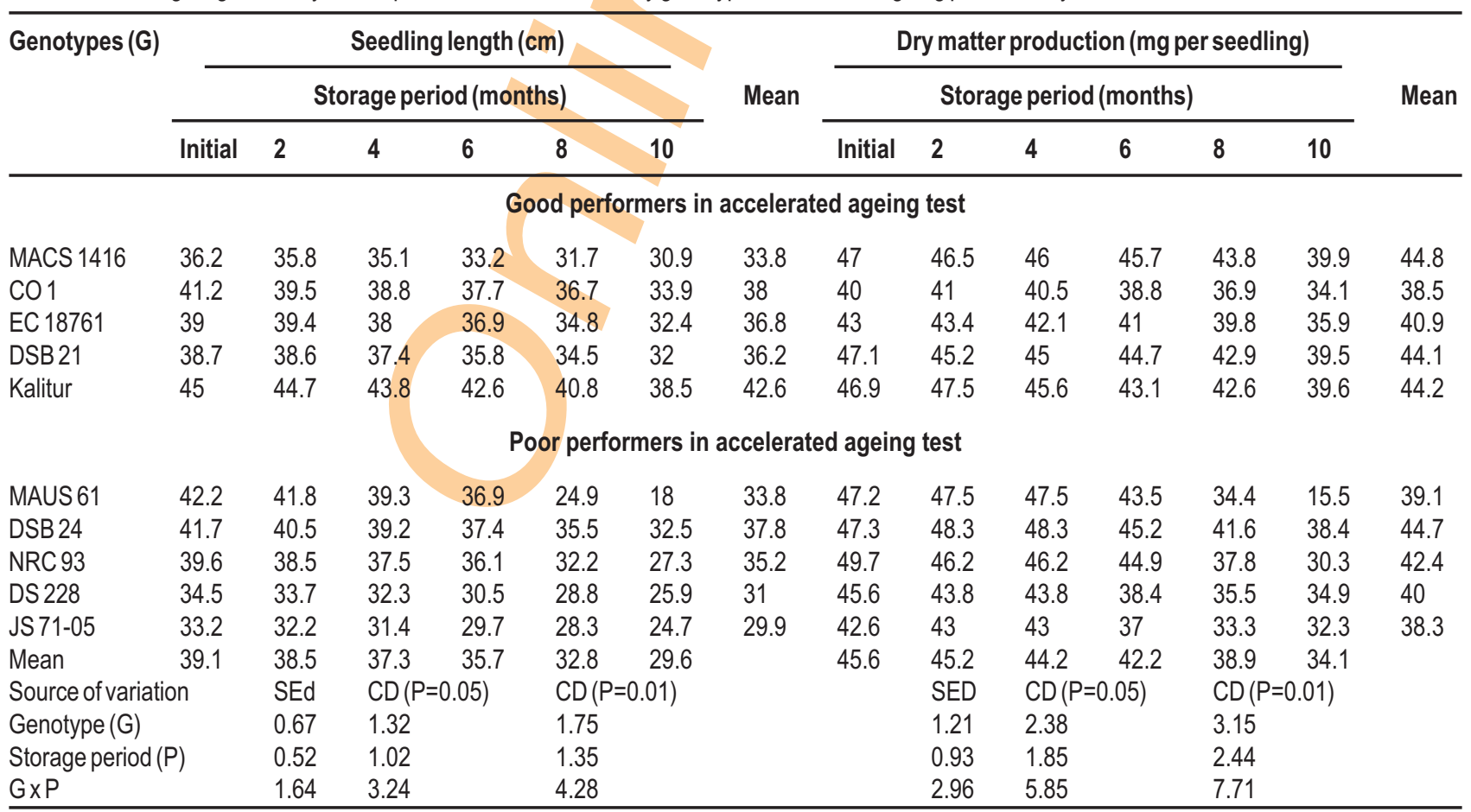


Table 3: Seedling vigour index I and II as influenced by genotypes and natural ageing period in soybean

\begin{tabular}{|c|c|c|c|c|c|c|c|c|c|c|c|c|c|c|}
\hline \multirow[t]{3}{*}{ Genotypes (G) } & \multicolumn{6}{|c|}{ Seedling vigour index I } & \multicolumn{7}{|c|}{ Seedling vigour index II } & \multirow{3}{*}{ Mean } \\
\hline & \multicolumn{6}{|c|}{ Storage period (months) } & Mean & \multicolumn{6}{|c|}{ Storage period (months) } & \\
\hline & Initial & 2 & 4 & 6 & 8 & 10 & & Initial & 2 & 4 & 6 & 8 & 10 & \\
\hline \multicolumn{15}{|c|}{ Good performers in accelerated ageing test } \\
\hline MACS 1416 & 3552 & 3510 & 3368 & 3155 & 2978 & 2654 & 3203 & 4608 & 4556 & 4418 & 4337 & 4119 & 3435 & 4246 \\
\hline CO1 & 3827 & 3633 & 3416 & 3246 & 3042 & 2711 & 3313 & 3720 & 3772 & 3564 & 3339 & 3061 & 2727 & 3364 \\
\hline EC 18761 & 3864 & 3783 & 3491 & 3287 & 2959 & 2692 & 3346 & 4257 & 4165 & 3872 & 3649 & 3380 & 2979 & 3717 \\
\hline DSB 21 & 3443 & 3360 & 3141 & 2934 & 2727 & 2497 & 3017 & 4187 & 3935 & 3780 & 3664 & 3392 & 3083 & 3674 \\
\hline Kalitur & 4232 & 4201 & 3983 & 3833 & 3593 & 3351 & 3865 & 4413 & 4465 & 4150 & 3877 & 3753 & 3445 & 4017 \\
\hline \multicolumn{15}{|c|}{ Poor performers in accelerated ageing test } \\
\hline MAUS61 & 4009 & 3759 & 3301 & 2769 & 847 & 90 & 2463 & 4479 & 4277 & 3901 & 3263 & 1168 & 78 & 2861 \\
\hline DSB 24 & 3713 & 3564 & 3212 & 2842 & 2520 & 1947 & 2966 & 4207 & 4248 & 3879 & 3433 & 2951 & 2305 & 3504 \\
\hline NRC 93 & 3447 & 3271 & 2922 & 2491 & 1998 & 681 & 2468 & 4322 & 3928 & 3568 & 3095 & 2345 & 757 & 3002 \\
\hline DS 228 & 3209 & 2935 & 2619 & 2284 & 1989 & 1503 & 2423 & 4236 & 3807 & 3389 & 2878 & 2449 & 2026 & 3131 \\
\hline JS 71-05 & 2991 & 2735 & 2478 & 2135 & 1899 & 1333 & 2262 & 3830 & 3657 & 3287 & 2665 & 2232 & 1747 & 2903 \\
\hline Mean & 3629 & 3475 & 3193 & 2898 & 2455 & 1946 & & 4226 & 4081 & 3781 & 3420 & 2885 & 2258 & \\
\hline \multicolumn{2}{|c|}{ Source of variation } & SED & \multicolumn{2}{|c|}{$C D(P=0.05)$} & \multicolumn{2}{|c|}{$C D(P=0.01)$} & & & SED & \multicolumn{2}{|c|}{$C D(P=0.05)$} & \multicolumn{2}{|c|}{$C D(P=0.01)$} & \\
\hline \multicolumn{2}{|c|}{ Genotype (G) } & 59.3 & \multicolumn{2}{|c|}{117} & \multicolumn{2}{|c|}{154.4} & & & 101.3 & \multicolumn{2}{|c|}{199.9} & \multicolumn{2}{|c|}{263.8} & \\
\hline \multirow{2}{*}{\multicolumn{2}{|c|}{$\begin{array}{l}\text { Storage period }(P) \\
\text { GxP }\end{array}$}} & 45.9 & \multirow{2}{*}{\multicolumn{2}{|c|}{$\begin{array}{l}90.7 \\
286.8\end{array}$}} & \multicolumn{2}{|c|}{$\begin{array}{l}119.6 \\
3784\end{array}$} & & & 78.4 & \multirow{2}{*}{\multicolumn{2}{|c|}{$\begin{array}{l}154.8 \\
4898\end{array}$}} & \multicolumn{2}{|c|}{204.3} & \\
\hline & & 145.3 & & & 378.4 & & & & 248.2 & & & 646.2 & & \\
\hline
\end{tabular}

Table 4 : Mobilisation efficiency and electrical conductivity as influenced by genotypes and natural ageing period in soybean

\begin{tabular}{|c|c|c|c|c|c|c|c|c|c|c|c|c|c|c|}
\hline \multirow[t]{3}{*}{ Genotypes (G) } & \multicolumn{6}{|c|}{ Mobilisation efficiency (\%) } & \multicolumn{7}{|c|}{ EC of seed leachate $\left(\mu \mathrm{cm}^{-1} \mathrm{~g}^{-1}\right.$ seed) } & \multirow{3}{*}{ Mean } \\
\hline & \multicolumn{6}{|c|}{ Storage period (months) } & \multirow[t]{2}{*}{ Mean } & \multicolumn{6}{|c|}{ Storage period (months) } & \\
\hline & Initial & 2 & 4 & 6 & 8 & 10 & & Initial & 2 & 4 & 6 & 8 & 10 & \\
\hline \multicolumn{15}{|c|}{ Good performers in accelerated ageing test } \\
\hline MACS 1416 & 73 & 71.5 & 69.5 & 66.1 & 63.6 & 58.8 & 67.1 & 82 & 85.6 & 90.4 & 98.4 & 110.9 & 121.3 & 98.1 \\
\hline Co1 & 68.1 & 66.4 & 64.2 & 60 & 57.6 & 51 & 61.2 & 85.7 & 93 & 100 & 108.6 & 115.2 & 126.6 & 104.8 \\
\hline EC 18761 & 71.5 & 69 & 65.7 & 60.4 & 58.1 & 53.2 & 62.9 & 84.7 & 91.9 & 101.4 & 109.8 & 118.6 & 127.4 & 105.6 \\
\hline DSB 21 & 67.2 & 65.4 & 61.1 & 59 & 55.9 & 52.4 & 60.2 & 80.4 & 90 & 96.1 & 105.9 & 113.3 & 126.9 & 102.1 \\
\hline Kalitur & 70.2 & 67.8 & 65.3 & 62.4 & 59.9 & 57.3 & 63.8 & 61.7 & 63.9 & 65.9 & 68 & 70.1 & 75 & 67.4 \\
\hline \multicolumn{15}{|c|}{ Poor performers in accelerated ageing test } \\
\hline MAUS 61 & 69 & 66 & 59 & 50.9 & 23 & 2.1 & 45 & 95.5 & 108.8 & 120.4 & 132.8 & 179.3 & 231.6 & 144.7 \\
\hline DSB 24 & 67.3 & 65 & 60.5 & 52 & 45.7 & 36.7 & 54.5 & 92.5 & 105.6 & 115.5 & 124 & 140.2 & 160.8 & 123.1 \\
\hline NRC 93 & 66.8 & 63.9 & 57.7 & 46.9 & 38.9 & 17.8 & 48.7 & 93.4 & 107.7 & 118.8 & 129.9 & 151.1 & 190.3 & 131.9 \\
\hline DS 228 & 68.6 & 65.6 & 60.6 & 50.6 & 42.5 & 34.5 & 53.7 & 89.6 & 102.8 & 110.3 & 125.9 & 142.9 & 161.4 & 122.1 \\
\hline JS 71-05 & 67.1 & 63.6 & 59 & 48.9 & 40.2 & 31.4 & 51.7 & 87.2 & 105.3 & 112.5 & 127.2 & 145.5 & 164.1 & 123.6 \\
\hline Mean & 68.9 & 66.4 & 62.3 & 55.7 & 48.5 & 39.5 & & 85.3 & 95.4 & 103.1 & 113.1 & 128.7 & 148.5 & \\
\hline \multicolumn{2}{|c|}{ Source of variation } & SED & $\mathrm{CD}(\mathrm{F}$ & $.05)$ & \multicolumn{2}{|c|}{$\mathrm{CD}(\mathrm{P}=0.01)$} & & & SEd & \multicolumn{2}{|c|}{$\mathrm{CD}(\mathrm{P}=0.05)$} & \multicolumn{2}{|c|}{$\mathrm{CD}(\mathrm{P}=0.01)$} & \\
\hline \multicolumn{2}{|c|}{ Genotype (G) } & 1.18 & 2.34 & & \multicolumn{2}{|c|}{3.1} & & & 1.81 & \multicolumn{2}{|c|}{3.6} & \multicolumn{2}{|c|}{4.76} & \\
\hline \multicolumn{2}{|c|}{ Storage period $(P)$} & 0.91 & 1.81 & & \multicolumn{2}{|l|}{2.4} & & & 1.4 & \multicolumn{2}{|l|}{2.78} & \multicolumn{2}{|l|}{3.68} & \\
\hline \multicolumn{2}{|c|}{$G \times P$} & 2.9 & 5.75 & & \multicolumn{2}{|l|}{7.6} & & & 4.45 & \multicolumn{2}{|l|}{8.82} & \multicolumn{2}{|l|}{11.66} & \\
\hline
\end{tabular}

EC increased with every storage period and recorded maximum value $\left(148.5 \mu \mathrm{S} \mathrm{cm}^{-1}\right)$ at the end of 10 months from $85.3 \mu \mathrm{S} \mathrm{cm}^{-1}$ (initial) (Table 4). Lipid peroxidation of membranes may lead to decline in membrane integrity that would increase the membrane permeability and electrical conductivity (Ratajczak and Pukacka, 2005). Kalitur showed the least increase in electrical conductivity over the ten months storage period (22\%), whereas MAUS 61 expressed drastic rise of $142 \%$. All the good storer/performer 

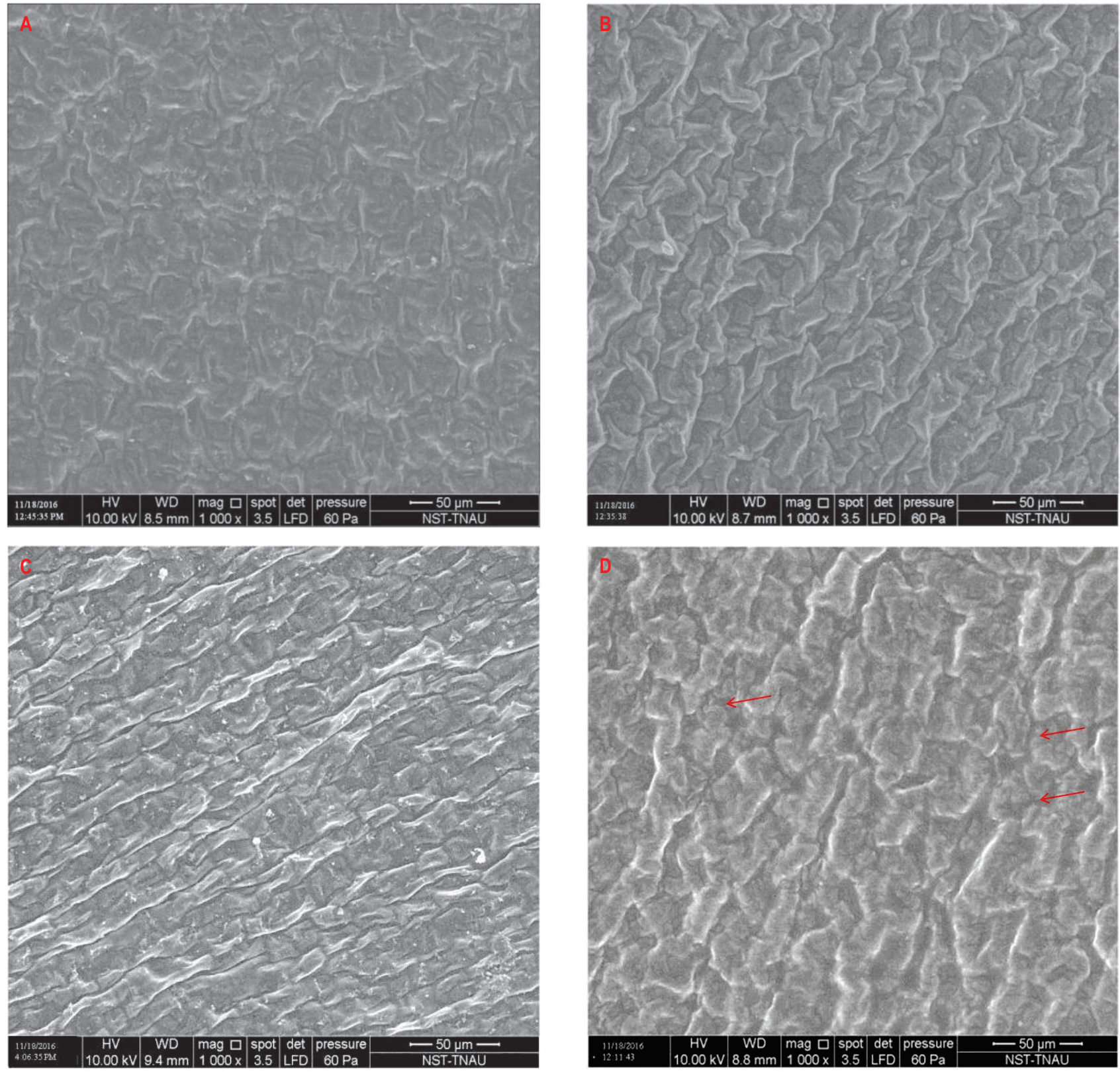

Fig. 1 : Histological changes in cotyledon of fresh and aged seeds of soybean genotypes: (A) Fresh seeds of DSB21; (B) Fresh seeds of MAUS61; (C) Aged seeds of DSB21 and (D) Aged seeds of MAUS61. Arrows indicate damage of cell membranes and lack of clear demarcation of cells in cotyledons of aged seeds of MAUS61.

genotypes maintained lower EC over the storage period compared to poor storer/performer genotypes.

Khan et al. (2004) reported that onion seeds exhibited very short life, and lost their germinability, vigour and viability due to loss of membrane integrity which leads to decreased vigour and ultimately viability of seeds. Demir et al. (2012) also reported a negative correlation of electrical conductivity with percentage of normal seedlings in radish seed lots. Similarly, Mavi et al. (2014) reported that electrical conductivity of seed soaked water after 17 and $24 \mathrm{hrs}$ of nine commercially acceptable seed lots (79-100\% standard germination) of salad radish cv. Fındık were negatively correlated with field emergence.

Scanning electron microscopic observations revealed that in fresh seeds of good storer (DSB 21), the cells in cotyledon were large, turgid and there was a clear demarcation of cells, however, in poor storer (MAUS 61) the cells were comparatively small and less turgid. Even after ten months storage, the integrity of cell membrane was maintained in DSB 21 and the extent of cell 

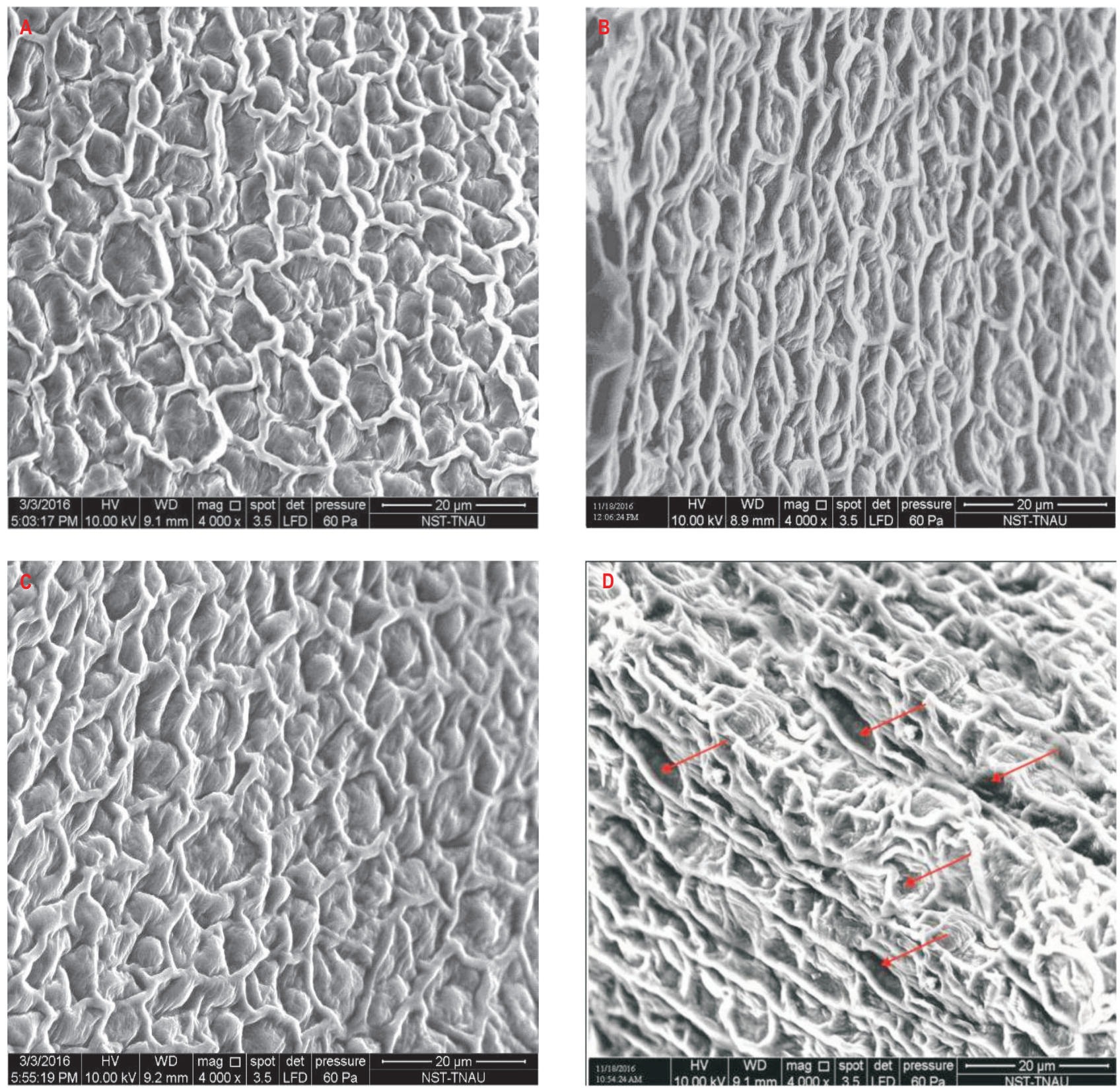

Fig. 2 : Histological changes in plumule of fresh and aged seeds of soybean genotypes: (A) Fresh Seeds of DSB21; (B) Fresh Seeds of MAUS61; (C) Aged Seeds of DSB21 and (D) Aged Seeds of MAUS61. Arrow symbol indicates collapse of cells and damage of cell membranes in plumule of aged seeds of MAUS61.

damage was less and turgidity of cells was maintained as that of fresh seed when compared to MAUS 61 wherein there was severe collapse of cells and the damage of cell membrane could be distinguishly visualised (Fig. 1). In plumule and radicle of fresh seeds of both the genotypes, the cells were compact and well arranged with clear demarcation and with intact membrane. After ten months of storage, the proportion of collapsed cells was more in MAUS 61 with membrane damage and also the cells were not expanded (Fig. 2, 3), which is the first sign of germination. It clearly indicates that cell elongation stage was affected in MAUS 61 due to dead cells at the root tip, whereas in DSB 21 cells were triggered and elongated.

Higher lipid peroxidation in MAUS 61 might have led to more generation of reactive oxygen species and further damage of cell membrane resulting in collapse and death of cells in cotyledon (Fig. 1) and embryonic axis (Plate 2, 3). Whereas, in DSB 21, cells exhibited better tolerance mechanisms for deterioration which 

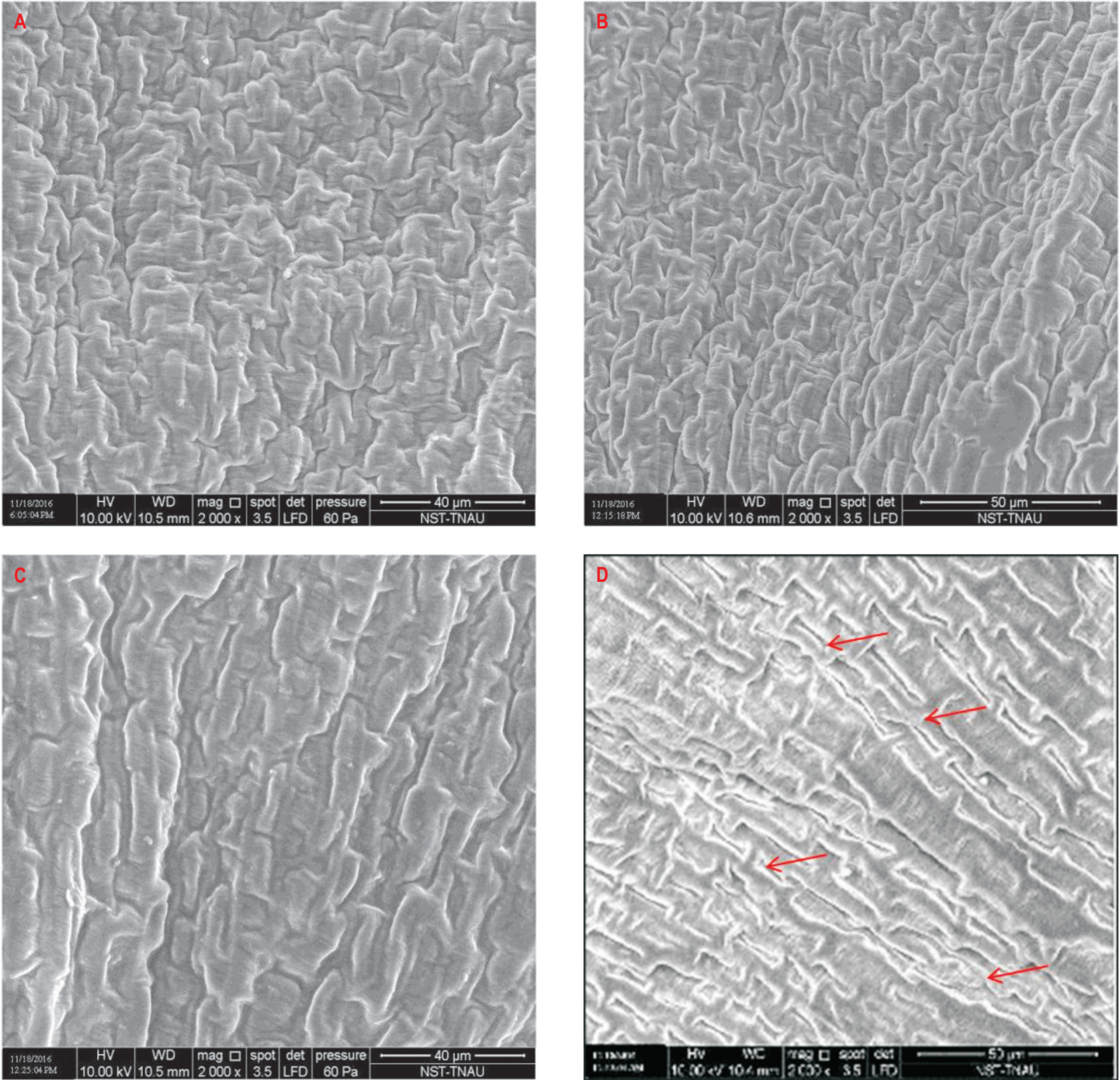

Fig. 3 : Histological changes in radicle of fresh and aged seeds of soybean genotypes: (A) Fresh seeds of DSB21; (B) Fresh seeds of MAUS61; (C) Aged seeds of DSB21 and (D) Aged seeds of MAUS61. Arrows indicate collapsed cells and membrane damages and no cell elongation in radicle of aged seeds of MAUS61.

leads to higher physiological quality indicating good correlation among histological changes and physiological quality. Kavitha et al. (2017) reported that cells of embryonic axis were clearly visible and found intact in fresh seeds while it was collapsed in both accelerated and naturally aged seeds of black gram. The damage was severe when ageing period was extended.

The present study confirms that poor storer genotypes of soybean maintained lower physiological seed quality during storage due to histological changes like disintegration of cell membranes of cotyledon and embryonic axis as they are less tolerant to biochemical changes.

\section{Acknowledgments}

Authors are thankful to the Department of Nano Science and Technology, Tamil Nadu Agricultural University, Coimbatore for providing SEM facility. We also thank Prof. Sundareshwaran 
(Seed Technology) for helping in seed multiplication of soybean genotypes atARS, Bhavanisagar.

\section{References}

Abdul-Baki, A.A. and J.D. Anderson: Vigour determination of soybean seed by multiple criteria. Crop Sci., 13, 630-633 (1973).

Anonymous: International Rules for Seed Testing. International Seed Testing Association, Bassersdorf, Switzerland (2007).

Anuja, G. and K.R. Aneja: Seed deterioration in soybean varieties during storage in physiological attributes. Seed Res., 32, 26-32 (2004).

Basu, S., S.P. Sharmaand M. Dadlani: Storability studies on maize (Zea mays $L$.) parental line seeds under natural and accelerated ageing conditions. Seed Sci. Technol., 32, 239-245 (2004).

Biabani, A., L.C. Boggs, M. Katozi and H. Sabouri: Effects of seed deterioration and inoculation with Mesorhizobium cicerion on yield and plant performance of chickpea. Aust. J. Crop Sci., 5, 66-70 (2011).

Demir, I., C. Cebeci and T. Guloksuz: Electrical conductivity measurement to predict germination of commercially available radish seed lots. Seed Sci. Technol., 40, 229-237 (2012).

Eksi, C. and I. Demir: The use of a shortened controlled deterioration vigour test in predicting field emergence and longevity of onion seed lots. Seed Sci. Technol., 39, 190-198 (2011).

Hampton, J.G. and D.M. TeKrony: Handbook of Vigour Test Methods. International Seed Testing Association, Switzerland (1995).

Harrington, J.F.: Seed storage and longevity. In: Seed Biology (Ed.: T.T. Kozlowski). Academic Press, New York, pp. 145-245 (1972).

Havstad, T., S. Aamlid and A. Lomholt: Evaluation of vigour tests for determination of seed storage potential in red clover (Trifolium pratensis L.) and timothy (Phleum pratense L.) Seed Sci. Technol., 39, 637-648 (2011)

Hosamani, J., M. Dadlani, I.M. Santha, M.B. Arun Kumar and S.R. Jacob: Biochemical phenotyping of soybean [Glycine max (L.) Merill] genotypes to establish the role of lipid peroxidation and antioxidant enzymes in seed longevity. Agrl. Res., 2,119-126 (2013).

Iqbal, N., A. Shahzad, M. Basra and K.U. Rehman: Evaluation of vigor and oil quality in cotton seed during accelerated aging. Int. J. Agri. Biol., 4, 318-322 (2002).

Jain, N., R. Kooper and S. Saxena: Effect of accelerated ageing on seeds of radish (Raphanus sativus L.). Asian J. Plant Sci., 5, 461-464 (2006).

Kannababu, N., S.S. Rao, B. Prabhakar, G. Shyamprasad, K. Srinivasa Babu, A. Dhandapani and J.V. Patil: Genetic variability for seed ageing and longevity among the advanced sweet sorghum genotypes and cultivars. Sugar Tech.,18, 100-104 (2016).

Kapoor, N., A. Arya, M.A. Siddiqui, A. Amir and H. Kumar: Seed deterioration in chickpea (Cicer arietinum L.) under accelerated ageing. Asian J. PI. Sci., 9, 158-162 (2010).

Kavitha, S., C. Menaka and M. Ananthi. Comparative study of physical, physiological, biochemical and histological changes due to accelerated and natural ageing of blackgram seeds. Int. J. Chem. Stud., 5, 1969-1973 (2017).

Khan, M.M., M.J. Iqbal, M. Abbas, H. Raza, R. Waseem and A. Ali: Loss of vigour and viability in aged onion (Allium cepa L.) seeds. Int. J. Agri. Biol., 6,708-711(2004).

Khatun, A., G. Kabir and M.A.H. Bhuiyan: Effect of harvesting stages on the seed quality of lentil (Lens culinarisL.) during storage. Bangladesh J. Agrl. Res., 34, 565-576 (2009).

Lima, W.A.A., A. Borém, D.C.F.S. Dias, M.A. Moreira and L.A.S. Dias: Lipoxygenase and physiological quality of soybean seeds during storage. Seed Sci. Technol., 38,767-771 (2010).

Mavi, K., F. Mavi, I. Demir and S. Matthews: Electrical conductivity of seed soak water predicts seedling emergence and seed storage potential in commercial seed lots of radish. Seed Sci. Technol.,42, 76-86 (2014).

McDonald, M.B.: Seed deterioration: Physiology, repair and assessment. Seed Sci. Technol., 27,177-237(1999).

Panse, V. G. and P. V. Sukhatme: Statistical Methods for Agricultural Workers. ICAR publication, New Delhi, p. 359 (1985).

Ratajczak, E. and S. Pukacka: Decrease in beech (Fagus sylvatica) seed viability caused by temperature and humidity conditions as related to membrane damage and lipid composition. Acta. Physiol. Plant, 27, 3-12 (2005).

Reddy, Y.T.N. and M.M. Khan: Effect of osmopriming on germination, seedling growth and vigour of khirni (Mimusops hexandra) seeds. Seed Res., 29, 24-27 (2001).

Shelar, V.R., R.S. Shaikh and A.S. Nikam: Soybean seed quality during storage:Areview. Agricultural Reviews, 29,125-131 (2008).

Srivastava, A.K. and K. Sareen: Physiology and biochemistry of deterioration in soybean seeds during storage. I. Mobilization efficiency and nitrogen metabolism. Seed Res., 2, 26-32 (1974).

Zhang, X.K., G.T. Yang, L. Chen, J.M. Yin, Z.L. Tang and J.N. Li: Physiological differences between yellow-seeded and blackseeded rapeseed (Brassica napus L.) with different testa characteristics during artificial ageing. Seed Sci. Technol., 34, 373381 (2006).

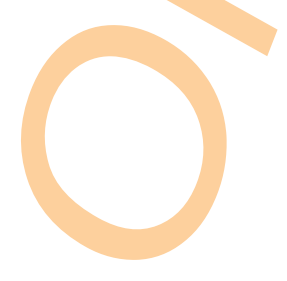

